\title{
ARTIGOS
}

\section{LUGARES RURAIS E ESPACIALIZAÇÃO DO CAPITAL: O AIRBNB COMO EVIDÊNCIA DAS URBANIDADES NO RURAL EM UM ESPAÇO EM GLOBALIZAÇÃO}

Joana Cruz de Simoni ${ }^{1}$

Pontifícia Universidade Católica do Rio de Janeiro

João Rua ${ }^{2}$

Pontifícia Universidade Católica do Rio de Janeiro

\section{Enviado em 4 mai. 2021 | Aceito em 15 jul. 2021}

Resumo: 0 artigo pretende discutir uma particular maneira de espacialização do capital. Para isso, analisa a presença do Airbnb enquanto elemento na produção de espacialidades rurais, constituindo-se em uma evidência de urbanidades no rural num contexto de globalização e planetarização do urbano, tomando-se como exemplo o município de Nova Friburgo, no estado do Rio de Janeiro. Demonstra-se como o espaço se integra e, ao mesmo tempo em que se desafiam as análises dicotômicas existentes, reafirmam-se assimetrias. Destaca-se como a presença de redes técnicas intensificam e aceleram um processo de inserção do lugar rural na escala global, através do seu modelamento para o consumo (como uma representação de espaço de lazer e turismo "antiurbano", porém, permeado de urbanidades) e sua apropriação por empresas globais, das quais o Airbnb é um exemplo.

Palavras-chave: espacialização do capital, urbanidades no rural, Airbnb, planetarização do urbano, globalização.

\section{RURAL PLACES AND THE SPATIALIZATION OF CAPITAL: AIRBNB AS AN EVIDENCE OF URBANITIES ON RURAL AREAS IN A GLOBALIZED SPACE}

Abstract: The article intends to discuss a particular way of spatialization of capital. It analyzes the presence of Airbnb as an element in the production of rural spatialities, constituting an evidence of urbanities on rural areas in a context of globalization and planetarization of the urban, analyzing, as an example, the municipality of Nova Friburgo - RJ. It demonstrates how the space is integrated and, at the same time that the existing dichotomous analyzes are challenged, old asymmetries are reaffirmed. It stands out how the presence of technical networks intensifies and accelerates a process of insertion of the rural place on a global scale, through its modeling for consumption (as a representation of leisure space and "anti-urban" tourism, however, permeated with urbanities) and its appropriation by global companies, whose Airbnb is an example.

Keywords: spatialization of capital, Airbnb, urbanities on rural areas, planetarization of the urban, globalization.

\section{LIEUX RURALES ET ESPACIALISATION DU CAPITAL: L'AIRBNB COMME UNE EVIDENCE DES URBANITÉES EN MILLIEU RURAL SOUS UN ESPACE EN MONDIALISATION}

Resumé: L'article entend évoquer un mode particulier de spatialisation du capital et, pour cela, il analyse la présence d'Airbnb comme élément de production de spatialités rurales, constituant une évidence d'urbanités en milieu rural dans un contexte de mondialisation et de planétarisation de l'urbain, en prenant, à titre d'exemple, la municipalité de Nova Friburgo, dans l'état de Rio de Janeiro. II montre comment l'espace est intégré et, en même temps que les analyses dichotomiques existantes sont remises en question, les asymétries sont réaffirmées. II surligne aussi comment la présence de réseaux techniques intensifie et accélère un processus d'insertion du lieu rural à l'échelle mondiale, à travers sa modélisation pour la consommation (comme représentation de l'espace de loisirs et du tourisme «antiurbain» pourtant imprégné d'urbanités) et son appropriation par des entreprises mondiales, dont Airbnb est un exemple.

Mots-clés: spatialisation du capital, urbanités en milieu rural, Airbnb, planétarisation de l'urbain, mondialisation.

1. Pós-doutoranda pela Pontifícia Universidade Católica do Rio de Janeiro. E-mail: joana.simoni@gmail.com, ORCID: https://orcid.org/0000-0001-5824-1147

2. Professor da Pontifícia Universidade Católica do Rio de Janeiro. Doutor em Geografia Humana. E-mail: joaorua@uol.com.br, ORCID: https://orcid.org/0000-0002-3907-8759 


\section{Introdução}

Este trabalho procura evidenciar algumas das atuais manifestações de espacialização do capital em lugares rurais, tomando como exemplo a expansão do Airbnb - uma plataforma na internet onde usuários podem alugar suas casas (inteiras ou de forma partilhada) para hóspedes, através da mediação do site. 0 artigo constitui-se em um desdobramento da pesquisa desenvolvida entre 2016 e 2019 (SIMONI, 2019)³ , a qual permitiu uma melhor empirização das reflexões aqui efetuadas. Buscase demonstrar um processo pelo qual o capital se espacializa - a partir de estratégias variadas -, mas sem fugir das suas bases estruturantes, da chamada acumulação primitiva: a espoliação e a despossessão (HARVEY, 2003a).

No presente trabalho, onde se discute o caso do Airbnb, é importante estabelecer/evidenciar algumas mediações entre as pontas da cadeia unidas pela referida empresa. De um lado, os acionistas dos fundos de pensão americanos, as empresas globais, bancos investidores; do outro, os pequenos proprietários, agricultores familiares, arrendatários, investidores urbanos e gestores de empreendimentos turísticos, os quais, sem necessariamente conhecerem o jogo de escalas do qual são participantes, possibilitam a espacialização do capital - mediada pelo Airbnb. Na verdade, desenvolvem-se, nesse processo, novas formas de espoliação e despossessão, agora inteiramente integradas à lógica da financeirização do espaço, explicitada na ação do capital fictício e em outras maneiras de se perceber a terra, a natureza e a paisagem como mercadorias. Em síntese, a pesquisa busca apontar para a relação entre acumulação primitiva, capital fictício e espoliação.

As profundas transformações espaciais das últimas décadas constituem-se resultado de processos complexos globais (industrialização, urbanização, reestruturação produtiva no sentido mais amplo) nos quais a abertura econômica, política e cultural vem expondo o país/o estado/as localidades a interações multiescalares e assimétricas cada vez mais intensas ao longo desse tempo. Tais transformações, entretanto, não se traduziram em nenhuma forma de igualização homogeneizadora a qual provocasse o desaparecimento das particularidades e singularidades espaciais. No entanto, redefiniram-nas, como, por exemplo, nas relações cidade-campo e urbanorurais; nas alterações do significado do agricultor e da agricultura na sociedade; na importância econômica, social, cultural e política dos atores locais (rurais e urbanos) no jogo de negociação que permanentemente reconstrói o lugar (MASSEY, 2000) e as territorialidades que nele se explicitam.

Assim, o processo de produção do espaço se complexifica ao se explicitar a insuficiência explicativa das oposições binárias, até pouco tempo dominantes - moderno/tradicional, atrasado/desenvolvido, campo/cidade, urbano/rural, concentração/dispersão, igualização/desigualização e outras mais. O que se observa é uma série de interações espaciais que "borram" as distinções (WOODS, 2009), aparentemente tão nítidas, e nos conduzem a pensar o espaço como totalidade em movimento (portanto, nunca completada) na qual a hibridez interconectadora desafia as definições, ressignificando os conceitos utilizados.

A partir de um diálogo com Hart (2018), este trabalho propõe uma análise relacional (e multiescalar) do Airbnb enquanto evidência de urbanidades no rural, processo esse que explicita a problematização das análises dicotômicas entre rural e urbano ou entre global e local. Segundo Gillian Hart (2018, p. 374-375), em vez de comparar objetos, eventos, lugares ou identidades pré-existentes - ou afirmar um processo geral como a globalização e comparar seus "impactos" -, buscaremos 
refletir como os processos-chave são constituídos em relação uns aos outros por meio de práticas carregadas de poder nas múltiplas arenas interconectadas da vida cotidiana.

Como sustentação das ideias que serão discutidas neste trabalho, procurou-se estabelecer três níveis de reflexão: em um primeiro nível, mais geral, sustenta-se que o espaço deve ser entendido como uma totalidade (sempre em movimento de totalização) que integra o urbano e o rural. Para esse nível, utilizam-se autores como Henri Lefebvre (2008), Gillian Hart (2018) e Milton Santos (1996). Um segundo nível de reflexão refere-se a duas ideias que procuraremos desenvolver: a de um rural em globalização - global countryside, explicitada em trabalhos como o de Woods (2007) e Maccarthy (2008) - e a planetarização do urbano, noção desenvolvida em Lefebvre (1989; 1999) e retomada em Merrifield $(2013,2018)$. Em um terceiro nível, de aproximação com o real, dialogaremos com Rua (2002; 2017; 2020), Simoni (2019), Murdoch (2006) e Santos (1996), compreendendo as redes técnicas (a Internet e, em específico, o Airbnb) como expressões dessas interações urbano-rurais.

$\mathrm{O}$ artigo se organiza em três seções, além dessa introdução e das considerações finais. $\mathrm{Na}$ próxima seção, apontamos algumas ideias-chave, as quais norteiam as perspectivas de espaço e lugar que fundamentam nossa reflexão. Na seção seguinte, discute-se a presença e os efeitos do Airbnb na produção do espaço contemporâneo e, em específico, de lugares rurais, tomando, como exemplo, o cenário de Nova Friburgo (RJ). Para melhor compreender alguns processos resultantes da relação entre essa empresa global e tais lugares, a última seção do artigo busca discuti-la à luz de três abordagens, as quais, em nossa visão, se complementam: a das urbanidades no rural, da planetarização do urbano e do rural em globalização.

\section{Situando o debate: miradas sobre o espaço e o lugar}

A concepção de espaço aqui considerada, integra-se à lógica de acumulação do capital, a qual funde o urbano e o rural (urbano+rural), ao mesmo tempo em que, contraditoriamente, fragmenta e hierarquiza o próprio espaço. Os investimentos do capital atuam, assim, como igualizadores e desigualizadores do espaço. Rural e urbano tornar-se-iam, também, distintos em termos de densidades e de disseminação dos elementos constitutivos do espaço.

Desse modo, o espaço será aqui compreendido à maneira de Hart (2018, p. 388), como uma totalidade fracamente estruturada, formada por um número infinito de processos mutuamente dependentes e em constante mudança. Tal conceituação de espaço como totalidade será reforçada pelas reflexões de Lefebvre (2008) - que a considera como aberta, cambiante e dialética - e se tornará fundamental para se compreender a crescente integração das relações urbano-rurais.

Percebemos o espaço como ponto de partida e como ponto de chegada nas reflexões aqui efetuadas. Enquanto ponto de partida, já se viu, será uma totalidade de totalidades, na qual o urbano e o rural se embaralham, se intercambiam e borram seus limites. Como ponto de chegada, o espaço será percebido em suas múltiplas qualificações, tanto nas áreas denominadas urbanas, quanto nas rurais. O processo geral será o mesmo: uma constante relação entre o capital (em suas múltiplas manifestações) e o espaço por ele fragmentado, homogeneizado e hierarquizado.

Retomamos uma reflexão sobre alguns elos entre espaço, lugar e totalidade. Em um primeiro momento, buscamos fazer uma sempre necessária inter-relação entre espaço e lugar, ou, nas palavras de Merrifield (1993), marcado pelo pensamento lefebvriano, nos debruçar sobre a relação espaço-lugar, sem que isso sugira que aquilo que chamamos de lugar possa ser "lido" a partir de um "reino" diferente que chamamos de espaço.

A relação espaço-lugar, para nós, dá-se associada à relação espaço e totalidade, que, conforme nos lembra Santos (1996, p.108), está a cada momento cindindo-se, "para reconstituir-se no momento 
seguinte, quando uma nova cisão renova o movimento". Carlos (2007, p. 14) nos auxilia a concluir essa inter-relação quando analisa o lugar no mundo moderno (e o mundo que se revela no e pelo lugar): ora, "no lugar encontramos as mesmas determinações da totalidade sem com isso eliminarse as particularidades".

É sob esse prisma que podemos afirmar que o capital se espacializa efetivamente nos lugares. Um lugar disperso para os acionistas unidos apenas pelo interesse no lucro de seus investimentos; um lugar de fluidez (de trânsito, de informação, de movimentações) do sistema financeiro; um lugar de comando para a empresa que lidera as conexões da rede em estudo (o Airbnb); um lugar de ação mais próxima para os investidores urbanos que "fixam" seu capital nesse tipo de aplicação; o lugar da vida cotidiana dos "do lugar" afetados indiretamente por essas interações multiescalares e diretamente pelo convívio com turistas e veranistas, pela mudança de hábitos, pelo contato com essas escalas, dos investimentos dos "de fora"4. A vida cotidiana desses sujeitos locais explicita/oculta movimentos muitas vezes silenciosos (na aceitação e resistência) ou silenciados pela capacidade de cooptação apresentada pela força do capital.

Para fundamentar nossa concepção de lugar recorremos a Ribeiro (2005); Santos (1996), Massey (2000) e Carlos (2007). Ribeiro (2005) ressalta que a noção de lugar perde sua potência se atrelada exclusivamente à escala local, quando não dialoga com sua natureza transescalar. No mesmo sentido, Santos (1996) discute como a noção de lugar não se circunscreve à noção de local, devendo sempre ser pensado em sua relação com outras escalas: "para apreender essa nova realidade do lugar, não basta adotar um tratamento localista, já que o mundo encontra-se em toda parte" (Santos, 1996, p.314). Na perspectiva do autor, é pelo lugar que percebemos empiricamente o mundo, assim, "cada lugar se define tanto por sua existência corpórea, quanto por sua existência relacional" (Santos, 1996, p.158).

O lugar é, na concepção de Massey (que busca escapar de dualismos em suas análises), sem fronteiras nítidas, heterogêneo, constituído de processos e conflitos. Assim, o "sentido de lugar" (MASSEY, 2000) contém, mas ultrapassa a ideia de enraizamento e identidade. Esse sentido progressivo de lugar é constituído por meio da mobilidade e da interação, conectando-o, necessariamente, ao mundo; esfumando o "dentro" e o "fora" do lugar. A leitura de Santos (1996) colabora para a compreensão das provocações de Massey: lugar e cotidiano aparecem enquanto noções indissociáveis - pensadas, sempre, no contexto da globalização.

Carlos (2007) destaca também a potencialidade do conceito de lugar para se compreender a racionalidade homogeneizante do processo de (re)produção e acumulação do capital, que, conforme a autora "não se realiza apenas a partir da produção de objetos e mercadorias, mas liga-se cada vez mais à produção de um novo espaço, de uma nova divisão e organização do trabalho, além de produzir modelos de comportamento que induzem ao consumo e norteiam a vida cotidiana" (p. 11). o lugar definido a partir dos entrelaçamentos impostos pela divisão (espacial) do trabalho, articulado e determinado pela totalidade espacial; portanto, não é uma forma autônoma dotada de vida própria, uma vez que sua reprodução se acha vinculada ao caráter social e histórico da produção do espaço geográfico global.

Para nós, interessa destacar, então, a concepção de lugar, a qual, em um diálogo com esses autores, culmine, como destacou Haesbaert (2017, p. 7), na proposta de Massey, em que, "[o lugar]

4 As aspas são necessárias pois, como Massey (2000), também questionamos o sentido de lugar que contraponha os "de fora" e os "de dentro", uma vez que é impossível excluir um "de fora" quando não existe um interior ou exterior bem definidos ou separados. Há, em vez disso, um conjunto de conexões constitutivas. A perspectiva analítica deste trabalho procura ressaltar as permanentes interações multiescalares, nas quais a simultaneidade da ação impede dicotomizações de qualquer natureza. Por outro lado, é necessário acentuar as assimetrias de tais escalas de ação no lugar e a partir dele. 
envolve sobretudo redes, conexões, encontros". Essa correlação que a autora elabora entre redes e lugares parece bastante adequada à exemplificação empírica que escolhemos para esta pesquisa. 0 Airbnb constitui-se em uma poderosa rede de conexões entre distintos lugares e escalas, evidenciando a assimetria das geometrias de poder (intensificadas por novas bases tecnológicoinformacionais), anunciadas por Massey já em 1993.

A essas reflexões teórico-conceituais, que compõem um primeiro momento metodológico do trabalho, segue-se um outro momento constituído como um método de investigação, no qual se explicita a problemática estudada, a espacialização dessa problemática, os sujeitos protagonistas dessa espacialização e as ações e intencionalidades que os movem nesse processo de (re)produção do espaço. Esse momento é marcado por uma interação dialética entre tais sujeitos, suas ações e as escalas de alcance dessas ações, que, neste trabalho, apenas enunciaremos.

Em nosso exemplo de estudo, analisamos as novas "impressões" técnicas no espaço em lugares rurais do município de Nova Friburgo, no estado do Rio de Janeiro, a partir da presença do Airbnb. Essas "impressões" evidenciam relações assimétricas entre "os do lugar" e "os de fora" - ao mesmo tempo em que evidenciam a dificuldade em demarcar tal distinção. Como sujeitos/sujeitados no lugar encontra-se uma grande diversidade de situações, isto é, um amálgama de interações atravessadas pelas classes sociais, questões de gênero, étnicas, de raça, entre outras. Neste trabalho, no entanto, buscaremos apontar algumas estratégias de espacialização do capital, a partir da mercadificação do lugar rural, que, ao mobilizar novas técnicas (em nosso foco de estudo, o Airbnb) emaranha os lugares rurais nas tramas da globalização capitalista-urbano-metropolitana.

O Airbnb como evidência de urbanidades no rural: proprietários ausentes e dinâmicas do rural em globalização

Como visto em Simoni (2019), ao discutir a globalização - e as consequências humanas deste processo -, Bauman (1999) levanta o debate acerca de uma dinâmica que intitula "proprietários ausentes". Em tempos de globalização, relata o autor, "a mobilidade tornou-se o fator de estratificação mais poderoso e mais cobiçado" (1999, p.16). A noção de proprietário ausente, em sua primeira versão, buscava dar conta daqueles proprietários - de terra - cujo único interesse era extrair renda, ou "produto excedente" de suas propriedades, sem que nela trabalhassem ou sequer habitassem. Ainda que ausentes (ou seja, negligentes quanto à vida cotidiana que ali exercia seu labor ou moradia), esses proprietários dependiam da eficiência do trabalho alheio (e da terra) para obtenção de sua renda. A terra, também, tinha limites e restringia (ainda que não de forma definitiva) a ausência do tal proprietário - em verdade, limitava sua mobilidade.

O atual momento de liquidez do capital, das formas de circulação e organização deste, eleva a desobrigação ou o deslimite dos ditos proprietários a outro patamar. Proprietários de uma empresa (mas não de seu solo) ou acionistas ("proprietários" de muitas empresas) veem o capital mover-se (e ampliar-se) livremente. Poucos são os limites de sua ampliação e movimentação - ainda que, sobre a terra (e os trabalhadores que dali tiram seu meio de vida), a pressão seja cada vez maior. Em outras palavras, a terra e os trabalhadores estão chegando cada vez mais perto de seus limites.

Na terminologia lefebvriana (2006), tal ausência faz-se presente: a pretensa liquidez da relação proprietário e propriedade (a ausência) concretiza-se numa negligência, cada vez maior, imposta aos lugares e às pessoas (a presença). Neste sentido, instala-se, nas palavras de Bauman (1999, p. 16), "uma nova assimetria entre a natureza extraterritorial do poder e a contínua territorialidade da 'vida como um todo"'. Tal assimetria, conforme discute o filósofo, marca um momento em que "o poder, agora desarraigado, capaz de se mudar de repente ou sem aviso, é livre para explorar e abandonar as 
consequências dessa exploração" (idem). Assim, tais proprietários estão livres (ou ausentam-se) das responsabilidades - localizadas nos lugares e cotidianos - sobre os efeitos de suas atividades. 0 capital, aparentemente, encontra-se sem amarras locais - ainda que dependendo, sob diversos ângulos, da existência do lugar (enquanto dimensão do espaço) e de seus atributos socionaturais.

A forma de organização do trabalho (seja dos proprietários, meeiros ou arrendatários) em muitas áreas rurais ainda se encontra, de certa maneira, atrelada à terra, que sofrem (a terra e os trabalhadores) os efeitos e as consequências da exploração. Aqui, destacamos: i) a exploração da terra e de seus recursos; ii) a exploração da saúde dos trabalhadores, levando-se em consideração as condições de trabalho (esforço físico e psíquico; uso de agrotóxicos, etc.); iii) as intempéries socioambientais; iv) transformações na autoestima e na memória coletiva dos moradores rurais em sua relação com a terra.

O mesmo não ocorre (ou ocorre sob dinâmicas quantitativa e qualitativamente distintas) com as empresas globais que se concretizam nesses lugares - através de sua virtualidade. O Airbnb é um exemplo emblemático desse processo: trata-se de uma plataforma online onde usuários podem alugar suas casas (inteiras ou de forma partilhada) para hóspedes, através da mediação do site. A empresa, com sede principal em São Francisco, nos Estados Unidos, tem acomodações listadas em cerca de 100 mil cidades e 191 países, hospedando, em sua plataforma, aproximadamente 6 milhões de acomodações (AIRBNB, 2019). Há duas formas de interação possíveis com a plataforma: a do anfitrião (usuário-locador), que disponibiliza sua propriedade ou parte dela (como um quarto) para aluguel; e a do hóspede (usuário-locatário) que escolhe e se hospeda em uma dessas propriedades ${ }^{5}$ (TAMBELLI, 2020).

Atualmente, a empresa tem valor de mercado superior ao de grandes redes de hotéis tradicionais (MUNKØE, 2017) e enquadra-se no escopo do que tem se denominado economia compartilhada - assim como a Uber (juntas, as duas são as maiores empresas deste nicho). Embora não se tenha uma noção definitiva dos modelos de negócio que constituiriam este ramo, a economia compartilhada seria: "1) baseada em peer-to-peer e não em business-to-consumer ou business-tobusiness e 2) baseada em transações de aluguel ou similares/compra de acesso em vez de uma mudança permanente de propriedade/venda" (JORGE, 2017). Já na visão de Schor (2015, p. 14), a economia compartilhada define-se como uma atividade econômica "Peer-to-Peer, ou pessoa a pessoa, facilitada por plataformas digitais"6. Apesar do teor positivo da noção de "compartilhar", muitos autores já traçam uma crítica sobre os rumos deste modelo de organização empresarial na produção do espaço contemporâneo. Srnicek (2017), por exemplo, nos apresenta o termo "economia de plataformas" ou "capitalismo de plataforma"7, que busca salientar esse modelo de exploração econômica dos dados. Dentre os diferentes tipos de plataforma ${ }^{8}$ às quais o autor se refere, o Airbnb faz parte daquilo que ele chama de "plataformas enxutas" (Lean platforms): aquelas que oferecem

5 Esse formato permite que a empresa lucre a partir das duas pontas envolvidas nessa interação, pois a estrutura de taxas mais comum na plataforma é dividida entre anfitriões (proprietários das acomodações) e hóspedes. Em geral, é deduzida de forma automática, do anfitrião, uma taxa de cerca de 3\%, calculada a partir do subtotal da reserva. Já os hóspedes pagam diretamente ao site uma taxa que varia de acordo com alguns fatores e que, geralmente, não ultrapassa 14,2\% do subtotal da reserva. Esse pagamento é sempre feito pela plataforma que, após deduzir os valores referentes às taxas, deposita na conta designada pelo anfitrião o valor referente à reserva.

6 Tradução nossa, do original: "I define the new sharing economy as economic activity that is Peer-to-Peer, or person-toperson, facilitated by digital platforms".

7 Concordamos com Brossat (2019) quando insere o Airbnb no contexto do capitalismo de plataformas, o qual, em sua argumentação, é capaz de conjugar três elementos: i) extração de renda a partir de um novo âmbito: o do partilhamento; ii) a externalização dos custos e riscos; iii) a desregulação (fiscal, trabalhista, entre outros).

8 São elas, além das "plataformas enxutas" (Lean platforms): Plataformas de publicidade (Advertising platforms), Plataformas de Nuvem (Cloud platforms), Plataformas industriais (Industrial platforms) e Plataformas de produto (Product platforms) (SENICEK, 2017). 
serviços ou produtos que não possuem ou não produzem, utilizando mão-de-obra e ativos dos usuários (sejam os que prestam serviços ou o que fazem uso desses serviços), em uma lógica altamente terceirizada (SRNICEK, 2017; SOUZA, 2021)

A dinâmica de funcionamento do Airbnb envolve, paradoxalmente, o proprietário ausente (ou, ainda, múltiplo e "invisível" - quando composto por uma rede de acionistas) e o proprietário presente, ou seja, aquele que sofre os impactos locais (da estrada não asfaltada à infiltração na casa) de seu empreendimento. Este formato amplifica e caracteriza os novos processos que vêm atuando nas transformações de alguns lugares rurais em globalização. Vai ao encontro daquilo que Santos (1996, p.11) aponta como a "horizontalidade [que] se completa com verticalidades formadas por pontos discretos povoados por agentes hegemônicos desinteressados da vizinhança, despreocupados da copresença".

O caso em tela, do Airbnb, mobiliza uma dinâmica parecida, embora sob outro contexto e envolvendo outras técnicas. Apesar de ser relativamente jovem (o projeto teve início em 2008, cf. Gant e Gago [2018]), a plataforma de hospedagem já alcança números exorbitantes. Além do sucesso econômico (com valor de mercado e faturamento na casa dos bilhões), das altas colocações nos rankings de start-ups mais bem-sucedidas da década, já são também numerosos os estudos que demonstram os efeitos desse modelo de hospedagem no espaço urbano.

Guttentag (2013, p. 8) nos mostra em suas pesquisas como, rapidamente, o número de acomodações - e de noites ocupadas - desse modelo de alojamento já disputava com as maiores cadeias internacionais de hotéis. De fato, o rápido crescimento da plataforma on-line trouxe consigo transformações sob diversos ângulos, que ultrapassam o mote da inovação de mercado (ou seu efeito negativo para os formatos clássicos de hospedagem). Mudanças nas preferências relacionadas às atividades turísticas (o autor fala no crescimento de um turismo informal), atreladas aos avanços nas tecnologias de comunicação e informação, trouxeram, também, mudanças na organização espacial - inicialmente, das grandes cidades turísticas. Dentre os casos frequentemente estudados, estão Nova York e cidades europeias como Barcelona e Lisboa (WACHSMUTH; ALEXANDER, 2018; GANT, 2016).

A relação entre essa nova forma de hospedar-se (e, na sua esteira, novas facetas do fazer turístico) e o processo de gentrificação é avaliada por diversos autores (como CHAMUSCA et al, 2019). Nos casos específicos das cidades citadas, os autores demonstram como há uma crescente conversão de moradias em acomodações para visitantes e turistas, o que engendra em impactos na oferta de moradia e, no extremo, coloca em pauta a turismofobia e a xenofobia - ao passo em que promovem a produção de uma paisagem urbana disneylândica (CHAMUSCA et al, 2019).

Assim, os primeiros efeitos socioespaciais do crescimento desse modelo de alojamento sentiram-se nas grandes cidades turísticas, onde, ainda que não exclusivamente por conta de tal modelo, intensificou-se um processo de gentrificação e de especulação imobiliária, levantando questões como o direito à moradia e a proliferação de imóveis ociosos. Esse processo, no entanto, implica, necessariamente, "um exercício ancorado à reticularidade que o espaço contemporâneo desenha" (PATRÍCIO, 2019). Essa reticularidade remete a uma trama que, conforme nos lembra a autora, se sobrepõe ao espaço físico. A presença da técnica (física e virtual) necessária para a existência e manutenção do modelo do Airbnb provoca tensões e transformações no espaço. De início, das grandes metrópoles. Mas, com inclinação a globalizar-se, encontra também nas localidades rurais espaços para consumo. Assim, "neste contexto, [...] a gentrificação se tem manifestado, cada vez mais, como um procedimento global, estimulada pelo surgimento de novos atores, tematizada por novas plataformas, e ativada por novos meios de circulação de indivíduos" (idem, grifos nossos). 
É por este prisma que podemos encarar a proposta por detrás do conceito da empresa: "reserve acomodações e experiências únicas" (AIRBNB, 2019), que já denuncia a pretensão em extrapolar os grandes centros urbanos. Embora a cidade do Rio de Janeiro configure-se como uma das que mais possui estabelecimentos deste tipo no mundo (em 2018 estava posicionada na quinta posição, com 30.302 acomodações ativas, cf. FORBES [2018]), atualmente, o crescimento proporcional do número de acomodações em alguns municípios menores - com maior extensão de áreas rurais - pode superar o de capitais metropolitanas.

Para citar um exemplo: entre 2016 e 2019, a quantidade de acomodações disponíveis na plataforma do Airbnb manteve-se praticamente estável na capital do estado do Rio de Janeiro (com exceção do pico ocasionado em virtude da realização dos jogos olímpicos na cidade, em 2016). Já em Nova Friburgo, município da Região Serrana do mesmo estado, com áreas rurais agrícolas, mas, também, destinadas ao turismo, viu-se, entre os mesmos anos, formar-se uma curva ascendente na quantidade de acomodações ofertadas através do site - partindo da ausência de hospedagens desse tipo até atingir a marca de quinhentas, três anos depois.

Podemos, então, avaliar que há tendência à saturação desse formato de acomodação na capital do estado, ao passo em que se encontra em franca ascensão no município que tomamos de exemplo. Além do crescimento bruto no número de acomodações em Nova Friburgo, podemos citar, à guisa de exemplo, a receita bruta mensal gerada por essa modalidade de hospedagem no referido município: de um total de $\mathrm{R} \$ 46.708$ de receita em maio de 2017, passa-se a R\$ 479.887 em maio de $2019^{9}$ - o que representa um crescimento de mais de $900 \%$ em 2 anos (823,83\%, se considerarmos a inflação no período ${ }^{10}$ ). Ao levar em consideração a sazonalidade turística na região, podemos notar que a maior receita bruta foi atingida no carnaval de 2019, quando chegou quase à soma de 1 milhão de reais ${ }^{11}$.

Talvez seja possível encarar esse processo como uma outra modalidade de estrangeirização da terra - não através da posse ou propriedade privada, mas pela presença deste "proprietário ausente" - o Airbnb. Em outras palavras, o lucro levantado a partir da oferta de hospedagem nessas localidades (ou seja: o consumo do lugar rural) se internacionaliza.

Explicita-se, com isso, a necessária atenção para os efeitos (sejam positivos ou negativos) de algumas das atuais formas de espacialização do capital, as quais afetam, sobremaneira, a vida cotidiana e a relação (econômica e/ou simbólica) dos moradores locais com a terra. Por um lado, percebem-se novas formas de alienação dos moradores locais com relação aos seus "instrumentos de vida" até há pouco dominados por eles. Por outro lado, são oferecidas outras oportunidades de trabalho e de consumo, complexificando cada vez mais a composição da renda familiar. Esse balanço é difícil de ser efetuado na medida em que os moradores locais não dispõem de todas as informações a respeito das relações de poder que se processam nas escalas supralocais.

Esses dados nos colocam, também, as seguintes questões: que tipos de acomodações são ofertadas (e, sobretudo, buscadas) na plataforma nesses lugares rurais? Em outras palavras, que representações do lugar rural têm atraído mais hóspedes ou turistas, através da mediação do Airbnb? A análise ${ }^{12}$ dos empreendimentos rurais listados na plataforma no município de Nova Friburgo

9 Dados obtidos em Airdna.com (AIRDNA, 2019).

10 Valor corrigido no período de maio de 2017 a maio de 2019, de acordo com o IGP-M (FGV).

11 No mês de março de 2019, a receita bruta gerada por acomodações desse tipo foi de R\$ 974.296,00, de acordo com dados do Airdna (2019).

12 A análise foi feita a partir de dados das hospedagens rurais no município que geraram a maior receita na plataforma, no ano de 2019, elaborada no contexto da tese de doutoramento (SIMONI, 2019) apresentada ao Programa de pós-graduação em Geografia da PUC-Rio, onde está mais profundamente desenvolvida. 
permitiu apontar algumas tendências relacionadas a essas questões, que se resumem na proposição a seguir: que rural está se buscando (material e simbolicamente), e por quem?

Destacamos, então, algumas ênfases que expressam as representações do espaço rural a partir das formas que são descritas tais acomodações:

i) Um rural físico-natural: Destacam-se esses lugares a partir de suas características naturais, evocando um rural ecológico e de belezas cênicas. "Natureza", "montanhas", "beira-rio", "serra", "vista panorâmica": esses são os termos acionados quando se busca apresentar essas acomodações - e onde estão situadas. De certa forma, encara-se o lugar rural como representante de uma única dimensão do espaço (a físico-natural), em uma perspectiva que se assemelha à preservacionista quando se trata da questão ambiental.

ii) Um rural anti-urbano: Evoca-se a noção de tranquilidade - opondo essas localidades a um urbano, agitado e caótico: termos como "descanso" e "sossego" buscam traduzir a "vida no campo". Assim, esse lugar/paisagem deveria ser consumido precisamente por representar a antítese do lugar urbano. A representação desse lugar rural idílico assemelha-se à produção de paisagens disneylândicas tal qual citado por Chamusca et al (2019).

iii) Um lugar rural permeado de urbanidades: A presença de comodidades ("Wi-fi, Netflix e TV a cabo"; "luxo"), expressões da necessidade das urbanidades, mesmo em momentos de "lazer" (outro termo muito acionado) longe dos centros urbanos (implicitamente representados como a antítese, portanto, do sossego e da natureza), aparece como uma outra representação desse lugar rural globalizado e tornado mercadoria: embora possa parecer contraditório com os perfis anteriormente traçados, essa contradição é a expressão da mercadificação do lugar rural forjado para o consumo das elites.

As amenidades presentes nas acomodações também vão ao encontro dos padrões enfatizados nas representações do rural apresentadas. A maioria possui televisão e acesso à internet por meio da tecnologia wi-fi. Um rural conectado, portanto, é mais atrativo e mais consumido - ainda que, paradoxalmente, também se espere sossego e, de certa forma, afastamento ou isolamento nessa experiência do rural.

Importante destacar que os empreendimentos de maior receita se localizam em área rurais ou nas margens de pequenos núcleos urbanos. Ao analisar esse fato, em conjunto com os tipos de acomodação que geram mais receita, pode-se inferir que a busca por esse modelo de hospedagem no município de Nova Friburgo está atrelada a uma forma específica de turismo - ou seja, para atender a uma demanda de uma representação específica do rural.

Encontramos, portanto, evidências de espaços rurais que McCarthy (2008) denomina pósprodutivistas, onde as maiores commodities produzidas seriam, em verdade, seus "usos orientados ao consumo" pelas elites. Assim, haveria a necessidade de uma produção de tipos particulares de paisagens e experiências rurais, baseadas em uma relação paradoxal com o urbano: estariam superficialmente opostas, mas fundamentalmente conectados (MCCARTHY, 2008). Tais áreas, portanto, estariam cada vez mais integradas à escala global, no que tange às formas da (re)produção do espaço e das relações sociais. 
Esse processo coloca-nos frente à contradição exposta por Harvey (2003b): ao passo em que se enfatizam as características "excêntricas" do lugar rural - qualidades únicas e insubstituíveis como marcas que possibilitam o rendimento monopólico, "nenhum item pode ser tão único ou tão especial a ponto de estar totalmente fora do cálculo monetário" (idem, p. 143). E, como a própria mercadologia exige a fungibilidade, tendendo a destruir qualidades únicas, encontramo-nos frente a uma mercadificação do lugar - e, em específico, do lugar rural - inserida na dinâmica da já exposta tríade lefebvriana: homogeneização, fragmentação e hierarquização.

Esta contradição apontada por Harvey é também trabalhada por Castrogiovanni (2007) enquanto um movimento dicotômico dos turistas que "solicitam, por um lado, a intocabilidade da natureza e dos elementos culturais do lugar turístico, mas, contraditoriamente, são nítidos os investimentos na culturalização da natureza, através do processo técnico-informacional, estereotipando o espaço turístico". Aproxima-se, assim, daquilo sobre o que refletia Silva (2017): "o homogêneo recai à equivalência, já que tornar igual implica, em um procedimento lógico-formal, tornar-se intercambiável. Torna-se equivalente, o que, em sua lógica no interior do movimento, se repõe nos termos da possibilidade da troca, no movimento inerente ao mundo da mercadoria".

O modelo do Airbnb subentende, também, a troca de informações a baixo custo através da internet, conforme ressalta Munkøe (2017). Neste sentido, a inovação não está em oferecer casas ou quartos para aluguel, mas na velocidade e larga escala em que isso é feito - e possibilitado pela tecnologia da informação. Reflitamos acerca da questão da multiescalaridade subjacente a esse processo e à concretude do lugar em meio ao processo de globalização. Coloca-se uma relação entre o global, a planetarização do urbano (expressão a ser aprofundada mais à frente) e o lugar, mediada, sobretudo, pela tecnologia informacional. Por meio dessa técnica suscita-se "a emergência de plataformas como o Airbnb que, enquanto ator, concretiza virtualidades" (PATRÍCIO, 2019, p. 38). A autora, ao sinalizar esse aspecto, dialoga com Latour (2005, p. 207-208), que, refletindo acerca da tecnologia da informação (e das técnicas e objetos enquanto portadores de agência), avalia sua inovação. Através dela, destaca o autor, faz-se visível (ou presente) o que antes existia apenas virtualmente.

A análise da presença desses empreendimentos nas áreas rurais suscita também outra questão: qual seria o efeito dessas empresas globais no projeto de multirendimentos das famílias agricultoras locais? Essas hospedagens são mantidas por essas unidades familiares? Sabe-se que o fenômeno turístico em localidades rurais é um dos maiores responsáveis pela diversificação das atividades exercidas pelas famílias rurais: para além da atividade agropecuária, atividades como hotelaria, beneficiamento e comercialização de produtos, ecoturismo, entre outras, seriam desempenhadas, também, por agricultores. A unidade produtiva e os membros da família (quando pensamos no âmbito da agricultura familiar) encontrariam, portanto, modos de (re)inventar as formas através das quais gerariam renda.

De fato, muitos estudos demonstram esse fenômeno ocorrendo em muitas localidades rurais do país. Na região apontada como exemplo, também podemos destaca-lo: as mesmas unidades familiares eram responsáveis, por exemplo, pela produção agrícola e pela comercialização ou "atravessamento" de produtos. Há, também, o caso do agroturismo, em que muitas propriedades agrícolas realizam visitas guiadas (pedagógicas e/ou turísticas), ampliando, assim, suas formas de reprodução social.

No entanto, é importante destacar que, quando observamos a presença e fomento da atividade turística mediada pela plataforma do Airbnb, constatamos que a maior parte das acomodações pertence (ou são gerenciadas) por moradores da capital do estado do Rio de Janeiro. Trata-se, em geral, de segundas residências ou casas de veraneio que se tornam estratégias de diversificação de 
rendimentos - porém, para moradores de áreas urbanas, através da oferta da possibilidade de consumo de representações específicas do lugar rural.

Ressalta-se, novamente a multiescalaridade na produção deste espaço: a empresa global (o Airbnb, neste caso) mediando o sistema de aluguel de um morador da metrópole em uma área rural de um município do interior do estado. Em que lugar se encontra o chamado "novo rural", nesse cenário?

De fato, esse processo pode ser analisado como uma atualização e intensificação (ou seja, mudança em quantidade e qualidade) de uma dinâmica que já vem ocorrendo em regiões rurais onde há forte exploração turística. Mayer (2003, p. 400), ao analisar o caso de Nova Friburgo, já concluíra:

O próprio turismo crescente tem favorecido a valorização da terra de tal modo que se torna mais atraente vendê-la ou alugá-la. [0 entrevistado] Dá o exemplo de áreas situadas em Rio Bonito e Macaé de Cima hoje pertencentes em $85 \%$ a pessoas de fora. Há diminuição de compra de terras por agricultores, sempre pela desvalorização da agricultura em função das proibições do IBAMA e também porque as próprias pessoas da terra consideram melhor negócio a construção de casas para alugar.

Essa dinâmica permanece e se intensifica atualmente. A venda de casas para pessoas "de fora" (com preços pautados pelo mercado urbano-metropolitano) segue levando à expulsão de famílias agricultoras para uma espécie de periferia rural. A presença do Airbnb, por sua vez, além de impulsionar esse processo, modifica a própria organização turística e hoteleira do lugar: antigos hotéis e tradicionais pousadas veem-se, por vezes, preteridas frente ao formato possibilitado pelo Airbnb e sua economia "compartilhada" (poderíamos questionar se não é, na verdade, "hiperconcentrada").

Ao mesmo tempo, observam-se algumas das clássicas maneiras de acumulação por espoliação, apontadas por Harvey (2003a, p. 121), quando retoma formulações marxianas e apresenta, por exemplo, a mercadificação, a privatização e a expulsão da terra. Como bem resume Ribeiro Junior (2014), marcado também pelas ideias de Harvey e de Marx, "a terra transformou-se em um ativo (uma riqueza). Onde este fenômeno pode ser facilmente visualizado já que estamos discutindo o capitalismo contemporâneo? Nas áreas urbanas e rurais a partir da apropriação da renda da terra, receitas a partir da propriedade privada da terra" (2014, p. 57).

Neste momento, podemos retomar ideias anteriormente apresentadas sobre as distintas maneiras da espacialização do capital, nas quais se destacam: a diversidade de investidores e de pessoas jurídicas ou físicas no gerenciamento desses investimentos (mobilizados pela dinâmica do Airbnb) e o caráter multiescalar dessa espacialização - evidenciando-se novas formas de gestão do espaço e do trabalho, integradas à lógica neoliberal do capitalismo atual.

Percebem-se, assim, as permanentes atualizações das maneiras de apropriação da renda da terra pelo capital, tal como observamos no estudo por nós realizado. A terra (considerada em sua dimensão física) e a rede de relações que aí se desenvolve - o escoamento da produção (seja pelos centros de abastecimentos, via atravessadores ou venda direta), negociações entre vizinhos e associações de produtores e moradores, por exemplo - enfatizam a dependência do lugar (e, aqui, em específico, o lugar rural) como meio de vida.

Ressalta-se, também, a relevância da abordagem das urbanidades no rural (como veremos a seguir) e da relação global-local na produção de lugares rurais. A presença dessa (e de tantas outras) empresas globais; a prevalência de turistas (e "gerentes") vindos da metrópole; bem como o tipo de amenidades que se busca quando se dirige a este espaço rural, exige que ajustemos as lentes para pensar as urbanidades, as ruralidades e globalidades nesse lugar. 
A internet enquanto técnica (desigual e seletiva, como nos lembra Santos [1996]) destaca-se como vetor de transformação multidimensional e multiescalar. Além de sua necessidade para a própria existência do modelo do Airbnb, para a mediação entre hóspedes e anfitriões e, ainda, a relevância da sua presença enquanto amenidade nas casas ofertadas, nos deparamos ainda com outra faceta de sua expressão. De acordo com dados do Airdna (2019), 77\% dos hóspedes que estiveram em acomodações de Nova Friburgo através da plataforma do Airbnb, eram usuários da rede social Facebook, os outros tinham contas vinculadas à Google ou ao Linkedin. São dados que indicam que a totalidade dos hóspedes está conectada a alguma rede social digital. Poderíamos, portanto, falar em uma multiescalaridade que se instala com a presença desses turistas e veranistas - uma simultaneidade de espaços vividos que se mescla com esses lugares rurais e que, ao mesmo tempo, impõe transformações a partir de relações de poder assimétricas. As perspectivas analíticas que conduzirão a seção seguinte do texto colaboram com o aprofundamento dessa reflexão.

\section{O rural em globalização, a planetarização do urbano e as urbanidades no rural: perspectivas analíticas}

Para melhor compreender essas "impressões" que refletem as relações (assimétricas e multiescalares) e que afetam sobremaneira a vida cotidiana nesses lugares rurais, utilizaremos três perspectivas analíticas que se complementam: urbanidades no rural, planetarização do urbano e rural em globalização. Essas ideias definirão duas escalas de reflexão: a primeira, integrando planetarização do urbano e rural em globalização; a segunda - escalas vivenciadas no lugar - será evidenciada pelos diversos elementos constitutivos das dimensões das urbanidades no rural que apresentaremos. Essas noções dão suporte à análise proposta: o Airbnb como evidência de um processo de transformação de áreas rurais pelos investimentos (desigualizadores) do capital.

Como já anunciado anteriormente, as noções de planetarização do urbano (e urbanização planetária) $)^{13}$ remontam ao pensamento de Lefebvre (1989; 1999), e são retomadas por Merrifield (2013; 2018). A partir do diálogo entre esses dois autores, destacam-se algumas ideias: i) o urbano não corresponde apenas ao ambiente construído das cidades; ii) a "sociedade urbana" é, também, um objeto teórico, possível, em processo de formação, uma "virtualidade iluminadora"; iii) a racionalidade urbana (capitalista) é difundida para as distintas maneiras de viver o cotidiano; iv) a difusão da racionalidade e do tecido urbanos, manifestam-se no domínio desse urbano sobre o rural, mesmo que mantidas as particularidades e singularidades em cada parcela do espaço analisada (sempre em transformação).

A planetarização do urbano expressaria, para nós, o movimento de difusão desigual do urbano pelo planeta. Reforça-se a ideia lefebvriana de que esse processo, além de apontar para uma possível homogeneização, indica também para sucessivas fragmentações e hierarquizações a que o espaço está sujeito, seja em áreas urbanas ou rurais. Conforme o autor, "o espaço está dividido em lotes que podem ser comprados e vendidos. Seu preço depende de uma hierarquia. É assim que o espaço social, ao homogeneizar-se, se fragmenta" (LEFEBVRE, 1989, p. 17) e se hierarquiza. Em nosso ponto de vista, a presença do Airbnb (seja em áreas urbanas ou rurais) expressa a simultaneidade da homogeneização capitalista com a fragmentação e hierarquização do espaço, como visto acima seja nos exemplos das grandes metrópoles, seja nas localidades rurais de Nova Friburgo.

13 Apesar de ser mais frequente o uso da expressão "urbanização planetária", preferimos a "planetarização do urbano" (tal como apresentada por Lefebvre [1989] em uma de suas últimas reflexões), por conter, em nosso ponto de vista, a perspectiva de um processo que ainda deverá ser completado - o urbano como uma virtualidade e uma racionalidade e não como algo já alcançado. 
Em nossa análise, a denominada planetarização do urbano, corresponderia à escala geral da difusão das relações capitalistas de produção pautadas pela mercadificação do espaço. Na escala local, observa-se uma intrincada diversidade de leituras particulares daquela virtual homogeneização. É nesta escala que se explicitam as fragmentações/hierarquizações atravessadas pelas questões de raça, gênero e classes sociais, as quais exigem uma permanente subjetividade nas reflexões efetuadas.

Explicita-se, assim, a necessidade de uma análise multiescalar do espaço, a qual nos conduz à segunda ideia-chave: um "rural em globalização", aportada sobretudo nos estudos de Woods (2007) e McCarthy (2008). Esse último autor, ao discutir os rumos dos espaços rurais na contemporaneidade - que ele denomina de rural pós-produtivista -, destaca a relação paradoxal desses com os espaços urbanos: apesar de superficialmente opostos, rural e urbano encontram-se fundamentalmente conectados, como vimos. Para ele, o "campo" vem se tornando, cada vez mais, uma commodity global, produzida para especificações exatas e padronizadas, em um número crescente de localidades (MCCARTHY, 2008, p. 129). O autor destaca, então, como o fenômeno da globalização alcança as localidades rurais, sobretudo a partir de uma dinâmica de extensão global do processo de transformação dos espaços rurais em mercadoria para as elites, que têm, como foco, áreas singularmente localizadas (MCCARTHY, 2008, p. 131) - ou seja, localidades permeadas de representações bastante específicas de ruralidades, como apresentamos quando da análise dos lugares rurais friburguenses e suas representações nas acomodações listadas no Airbnb.

Woods (2007) introduz a noção de "campo global", a qual representaria os últimos resultados ou alcances do processo globalizador. O autor é enfático ao afirmar que as características desse "campo global" se encontram apenas parcialmente articuladas, em localidades rurais particulares. Assim, reflete sobre um processo de reconstituição dos lugares rurais sob a globalização que, a partir de interações multiescalares e plurais (local, global, humanos, não-humanos, etc.), produzem novas formas espaciais híbridas. Interessante o destaque, também efetuado pelo autor, de que a política da globalização não pode ser reduzida à dominação ou subordinação, mas sim a uma política de negociação (WOODS, 2007, p. 485), além do importante realce aos efeitos geograficamente desiguais da globalização em localidades rurais.

Para nós, o "campo global" ("global countryside", no original) de Woods (2007) e McCarthy (2008) será compreendido como um rural em globalização, isto é, um rural em processo de integração multiescalar entre o lugar (rural) e o global. Aí se evidenciariam algumas das mais recentes maneiras de dominação do espaço pelo capital, afetando a vida das populações locais, a partir da mobilização de novos instrumentos e dinâmicas (dos quais o Airbnb é um exemplo) que acentuam a acumulação por espoliação/despossessão, tal como apresentada por Harvey (2003a).

A ideia das urbanidades no rural contribui para a compreensão dos processos apontados, estando, portanto, relacionada às noções de planetarização do urbano e do rural em globalização. De forma sintética, podemos compreender as urbanidades no rural como manifestações (materiais ou imateriais) de processos ligados ao urbano em espaços rurais.

Como vimos em Rua e Simoni (2020) e em Rua (2020) estas manifestações são evidências da multidimensionalidade do espaço, ou seja, expressam-se a partir de múltiplas dimensões (compostas por diversos elementos), das quais apontamos: a dimensão técnica (na qual destacamos as redes técnicas, tais como Airbnb que aqui apresentamos), a socioeconômica, a físico-natural e a simbólico-cultural - embora não se esgotem, aí, as possíveis dimensões do espaço ${ }^{14}$. Importa 
ressaltar que tais dimensões, contendo alguns elementos evidenciadores das urbanidades no rural, não podem ser compreendidas autonomamente uma em relação às demais. Todas se atravessam mutuamente, evidenciando a multidimensionalidade do espaço e das ações e intencionalidades engendradas e vivenciadas pelos sujeitos que o produzem. Tais ações e intencionalidades serão efetuadas por sujeitos contraditoriamente integrados pelas lógicas multiescalares que as mediam. Esse complexo quadro de interações subjetivas desdobra-se nas denominadas urbanidades no rural, cada uma podendo ser analisada simultaneamente per se, na dimensão à qual está integrada e no conjunto multidimensional que vai constituir a empirização do trabalho. Por outro lado, os elementos constitutivos de cada dimensão não são exclusivos dela. Assim, essas manifestações/elementos podem ser entendidas como maneiras de espacialização do capital em áreas rurais e, contraditoriamente, esses mesmos elementos podem constituir-se em instrumentos de resistência e de antagonismo àquela espacialização.

Nesse ponto é possível efetuar uma reflexão sobre a importância das técnicas, das redes e da escala. De início, podemos lembrar de Santos (1996, p. 25), quando escreve que as técnicas se apresentam como um elemento de propagação desigual e seletiva no espaço. Santos (1996, p. 176) assinala, também, que elas podem explicitar-se na forma de redes e ser analisadas segundo duas grandes matrizes: "a que apenas considera o seu aspecto, a sua realidade material, e uma outra, onde é também levado em conta o dado social. A primeira atitude leva a uma definição formal. Mas a rede é também social e política, pelas pessoas, mensagens, valores que a frequentam”. Muitas vezes essas redes se apresentam como redes técnicas que reconfiguram o espaço (rural + urbano).

Nessa mesma direção, Murdoch (2006, p. 181) ressalta que as redes ampliam a complexidade do espaço rural. Segundo o autor, é necessário compreender a relação entre redes e suas combinações nas localidades rurais, nas quais interagem elementos "endógenos" e "exógenos", "localizados" e "globalizados". Alerta o autor que essas redes podem afetar as relações de sociabilidade, por exemplo, enfraquecendo tradições comunitárias ou representando novas valorizações do rural e de sua vida cotidiana, explicitando, assim, algumas das diversas contradições que marcam o jogo de escalas entre o lugar rural e o capitalismo global.

Apoiando-nos em Haesbaert (2014), compreendemos que a rede se coloca como um "componente indissociável de nossa concepção relacional de espaço, quando sua manifestação se dá a partir da dominância de uma lógica reticular, daí a possibilidade de falar hoje em território-rede, lugar-rede" (p. 40). Para nós, parece estabelecer-se uma relação entre a empresa Airbnb e sua expressão territorial em rede; ao mesmo tempo o lugar rural alcançado e transformado pela mesma empresa pode ser apreendido como um lugar-rede. Assim, neste trabalho, parte da região serrana fluminense sofre a ação territorializadora da referida empresa, ação essa que se estende à escala

onde as atividades rurais são realizadas (aspectos físico-naturais, aspectos geomorfológicos e climáticos - carreamento de solos, deslizamentos, enchentes, etc.); b) ordem simbólico-cultural: memória coletiva e valorização da tradição, existência (ou não) de um localismo "conservador", convivência com o turismo rural e o veraneio, autoestima, relação com a natureza em seus aspectos imateriais, as percepções ecológico-ambientais e relações mais efetivas com os territórios da vida (populações indígenas, quilombolas, camponeses, etc.); c) ordem socioeconômica: dominação capitalista do espaço, conflitos entre o valor de uso e o valor de troca, renda territorial e preço da terra, importância da propriedade da terra (privada, pública ou comunitária), renda gerada pelo turismo, criação de novos empregos, presença de indústrias (ligadas ou não à produção agrícola), assistencialismo oficial e de ONGs, consumo e consumismo, associativismo, participação política e movimentos reivindicatórios; d) ordem técnica: adoção de novas tecnologias, inclusive de informação, presença de produtos agrícolas diferenciados, formas de comercialização que integram o lugar a redes mais amplas de raiz metropolitana e internacional, saneamento básico e coleta de lixo, existência de supermercados, estudos sobre a poluição da água e do lençol freático, cuidados no uso de agrotóxicos". 
vivenciada nos lugares rurais - poderíamos falar, também, em uma manifestação do capitalismo de plataforma já mencionado.

Em uma outra perspectiva a respeito das redes enquanto qualificadoras do espaço, Lencioni (2010, s.p.) contribui nessa discussão ao propor que:

\begin{abstract}
as redes são mediações, mas também momentos da produção, produtoras de um novo espaço. Podem ser materiais, como uma estrada ou imateriais, como as redes virtuais. Atualmente, essas tendem a crescer, a se diversificarem e a se tornarem mais complexas porque correspondem a necessidades e estratégias contemporâneas da reprodução do capital.
\end{abstract}

A relação entre as redes e as técnicas demonstram as interações multiescalares (associadas à planetarização do urbano e ao rural em globalização). Assim, o Airbnb se apresenta como uma rede virtual territorializada, constituindo-se como uma exemplificação das urbanidades no rural, que pressupõem, como foi visto, a multiescalaridade da ação. Isso aponta para a tendência já enunciada por Santos (1996) de uma "união vertical dos lugares", onde as redes se estabelecem "ao serviço do grande capital" (idem, p. 194).

\title{
Considerações finais
}

Num diálogo profícuo com Woods (2007), reiteramos que a ação de redes globais e de sujeitos enseja a disputa do/no próprio lugar, transcendendo a escala, ampliando as geometrias de poder através das quais os lugares rurais são constituídos, transformados e valorizados. Em nossa perspectiva analítica, mais uma vez fica explicitada a importância das urbanidades no rural ao demonstrarem tais assimetrias de poder e, portanto, a prevalência do urbano/capitalista/técnico sobre o rural, mesmo que em permanente hibridização de urbanidades e ruralidades.

Novamente, é necessário ressaltar a crescente integração do espaço (urbano+rural) no qual a hibridez entre elementos constitutivos da urbanidade e da ruralidade se mesclam e "borram" seus limites. Neste ponto, podemos recorrer a Merrifield (2018) quando aponta o transbordamento do urbano sobre o rural, ao escrever que o espaço urbano, ao se expandir, enreda o espaço rural e desemaranha a vida cotidiana nessas localidades. Assim, ainda seguindo ideias do autor, mais uma vez marcado pelo pensamento de Henri Lefebvre, encontraríamo-nos diante de uma sociedade urbana difusiva, desvinculada e aparentemente planetária em seu alcance, para além de qualquer separação urbano-rural. Daí a pertinência das perspectivas analíticas - planetarização do urbano, rural em globalização e urbanidades no rural - para uma melhor compreensão da complexidade das atuais relações urbano-rurais, aqui exemplificadas pela rede do Airbnb e sua presença em parte da região serrana fluminense.

Como escrevem Kato e Leite (2020), "as grandes corporações transnacionais [globais] seguem desempenhando um papel central na promoção dos negócios com terras, com a formação de cadeias cada vez mais oligopolizadas e financeirizadas". É nessa perspectiva que percebemos o Airbnb como uma empresa global, com atuação marcante no mercado de terras e na vida cotidiana dos moradores rurais de algumas áreas do município de Nova Friburgo, que aqui estudamos, procurando explicitar mais uma maneira de espacialização do capital.

Cabe relembrar a reflexão efetuada em Rua (2011), sobre como as contradições se evidenciam como desafios para a agenda de pesquisa, que buscam caminhar para a solução de conflitos (abertos ou latentes), fruto de uma lógica centralizadora na dispersão, fragmentadora e hierarquizadora (em todas as dimensões), expropriadora (do trabalho e da terra) e que, ao hipervalorizar o consumo (no 
urbano e no rural), conduz a uma inclusão precária e forçada, com fortes repercussões espaciais. A televisão e a internet estão em toda a parte; o saneamento básico, o tratamento da água, a saúde e a educação permanecem precários e grandes constrangedores da qualidade de vida nas áreas rurais fluminenses, mas, como sabemos, também nas áreas urbanas. Ao identificar esses problemas, os moradores locais podem alterar sua percepção crítica e engajar-se em movimentos ou mobilizações que conduzam de maneira explicita ou silenciosa (VILLULLA, 2017) a um processo de contestação ao capitalismo e às suas formas atuais de espacialização.

Em nosso ponto de vista, o processo analisado - e sua inclinação à homogeneização - não anula as leituras particulares efetuadas pelos moradores do lugar rural, produzindo, assim, espacialidades ao mesmo tempo rurais e urbanas em áreas rurais. Remetemos a Santos (1996), quando diz que "o novo não é difundido de maneira generalizada e total. Mas, os objetos técnicoinformacionais conhecem uma difusão mais generalizada e mais rápida do que as precedentes famílias de objetos. [...], sua presença, ainda que pontual, marca a totalidade do espaço".

Essa produção do espaço é fortalecida pela multiescalaridade da ação daqueles envolvidos em tal produção. A globalização, a técnica, a planetarização do urbano, mesclam-se nas escalas vivenciadas no lugar rural sem destruir suas características, embora alterando-as profundamente. Não se trata de um "novo rural", mas de um rural em permanente transformação pela sua integração com o urbano em planetarização. 


\section{Referências}

AIRBNB. (2019) About us. Disponível em: https://press.airbnb.com/about-us/. Acesso em: 12 de maio de 2019.

AIRDNA. (2019) AirDNA MarketMinder. Disponível em: https://www.airdna.co/vacation-rentaldata/app/br/rio-de-janeiro/nova-friburgo. Acesso em: 6 de junho de 2019.

BAUMAN, Z. (1999) Globalização: as consequências humanas. Rio de Janeiro: Jorge Zahar.

BROSSAT, I. (2019) Airbnb, la ciudad uberizada. Pamplona: Katakrak Liburuak. 148p.

CASTROGIOVANNI, A.C. (2007) O lugar da Geografia no entre-lugar do espaço turístico: uma viagem complexa. Scripta Nova. Revista Electrónica de Geografía y Ciencias Sociales. Barcelona: Universidad de Barcelona, v. XI, n. 245.

CHAMUSCA, P., MENDES, T., CARVALHO, L., \& FERNANDES, J. A. R. (2019) Geografias da Airbnb: as escalas, os efeitos e as opções. In IV Conferência em Políticas Públicas, Planeamento e Desenvolvimento Territorial-Descentralização \& Desenvolvimento: livro de artigos.

FORBES. (2019) 12 cidades mais populares no Airbnb. 8 de agosto de 2018. Disponível em:https://forbes.uol.com.br/listas/2018/08/12-cidades-mais-populares-no-airbnb/\#foto5. Acesso em 05 de agosto de 2019.

GANT, A, GAGO, A. (2018) Airbnb, investimento imobiliário e a crise de habitação em Lisboa. In: ESTEVENS, A., MATOS, F., NEUPARTH, S. (org.). Criar Corpo, Criar Cidade. Lisboa: Centro de Estudos Geográficos, v. 2, p. 15-22.

GANT, A. C. (2016) Holiday Rentals: The New Gentrification Battlefront. Sociological Research Online, v. 21, no. 3, p.112-120.

GUTTENTAG, D. (2013) Airbnb: disruptive innovation and the rise of an informal tourism accommodation sector. Current Issues in Tourism, v. 18, n. 12, p. 1-26. HAESBAERT, R. (2014) Viver no limite: território e multi/transterritorialidade em tempos de in-segurança e contenção. RJ: Bertrand. (2017) Lugares que fazem diferença: Encontros com Doreen Massey. Geographia, Niterói, v.

19, $\mathrm{n}$. 40.4 Disponível em: <http://www.geographia.uff.br/index.php/geographia/article/view/1191/733>. Acesso em 29 de março de 2021.

HART, G. (2018) Relational comparison revisited: Marxist postcolonial geographies in practice. Progress in Human Geography, Londres: Sage Publications, v. 42, p. 371-394.

HARVEY, D. (2003a) O "novo" Imperialismo: acumulação por espoliação. Nova lorque: Oxford.

(2003b) A arte de lucrar: globalização, monopólio e exploração da cultura. Por uma outra comunicação. Rio de Janeiro: Record, p. 139-171.

JORGE, C. (2017) Economia partilhada e consumo colaborativo com quem? Como a presença do Airbnb afeta os preços dos imóveis residenciais em Lisboa e no Rio de Janeiro. Dissertação de Mestrado em Economia Internacional e Estudos Europeus. Universidade de Lisboa. Lisboa.

LATOUR, B. (2005) Reassembling the social: an introduction to actor-network theory, Oxford University Press.

LEFEBVRE, H. (1989) Quand la ville se perd dans une métamorphose planétaire. Le Monde Diplomatique, Maio $1989 . \quad$ Disponível em: https://www.mondediplomatique.fr/1989/05/LEFEBVRE/41710. Acesso em 13 de julho de 2020. (1999) A revolução urbana. Belo Horizonte: UFMG.

A produção do espaço. (2008) Original: La production de l'espace.1991; 4e éd. Paris: Éditions Anthropos, 2000). Tradução: Doralice Barros Pereira e Sérgio Martins. 
(2006) La presencia y la ausencia. Contribución a la teoría de las representaciones/Henri Lefebvre; trad. de Óscar Barahona y Uxoa Doyhamboure - México: FCE. 305 p.

MACCARTHY, J. (2008) Rural geography: globalizing the countryside. Progress in Human Geography, Londres: Sage Publications v. 32, p.129-37.

MASSEY, D. (1993) Power-geometry and a progressive sense of place. In: BIRD, J. et al. (Org.) Mapping the future: local cultures, global change. Londres: Routledge.

(2000) Um sentido global de lugar. In: ARANTES, Antônio (Org.) 0 espaço da diferença. Campinas, SP: Papirus, p. 176-185.

(2008) Pelo espaço: uma nova política da espacialidade. Rio de Janeiro: Bertrand

Brasil. $312 \mathrm{p}$.

MAYER, J. (2003) Raízes e crise do mundo caipira: o caso de Nova Friburgo. Tese (Doutorado em História). Universidade Federal Fluminense, Niterói, RJ.

MERRIFIELD, A. (1993) Place and Space: A Lefebvrian Reconciliation. Transactions of the Institute of British Geographers, New Series, Vol.18, n²4, p.516-531, 1993.

. (2013) The Urban Question under Planetary Urbanization. International Journal of Urban and Regional Research, v. 37, p. 909-922.

1607.

(2018) Planetary urbanisation: une affaire de perception. Urban Geography, n. 39, v. 10, p. 1603-

MUNKØE, M. M. (2017) Regulating the European sharing economy: State of play and challenges. Intereconomics, v. 52, n. 1, p. 38-44.

MURDOCH, J. (2006) Networking rurality: Emergent complexity in the countryside. In: CLOKE, P., MARSDEN, T. AND MOONEY, P. (Orgs.). Handbook of rural studies. London: Sage.

PATRÍCIO, C. A (2019) Gentrificação como Procedimento Global. In: SMANIOTTO, C. e MENEZES, M. (Eds). Neighbourhood \& City - Between digital and analogue perspectives | Bairro \& Cidade - Entre perspetivas digitais e analógicas. Lisboa: Edições Universitárias Lusófonas, p. 35-45.

Ribeiro, A. C. T. (2005) Sociabilidade, hoje: leitura da experiência urbana. In: CADERNO CRH, Salvador, v. 18, n. 45, p. 411-422, Set./Dez.

RIBEIRO JUNIOR, J. A. (2014) Acumulação Primitiva, Capital Fictício E Acumulação Por Espoliação: Introdução A Uma Leitura Geográfica Da Economia Capitalista Contemporânea. Revista Tamoios, São Gonçalo (RJ), v. 10, n. 1, P. 55-66.

RUA, J. (2202) Urbanização em áreas rurais no Estado do Rio de Janeiro. In: MARAFON, G. J. \& RIBEIRO, M. F (Orgs.). Estudos de geografia fluminense. Rio de Janeiro: UERJ, p. 43-70.

(2011) A complexa simultaneidade da integração e distinção entre o urbano e o rural: retomando um debate no espaço de metropolização no estado do Rio de Janeiro. GeoPUC, Rio de Janeiro, v. 4, n. 7, p. 1-47.

. (2017) No estado do Rio de Janeiro. In: O espaço e a metropolização: cotidiano e ação. Orgs: FERREIRA, A.; RUA, J.; MATTOS, R. C. Rio de Janeiro: Consequência, p. 443-486.

(2019) Metropolização do espaço, urbanidades no rural e novas ruralidades. In: MARAFON,

Glaucio José; CHELOTTI, Marcelo Cervo; PESSÔA, Vera Lúcia Salazar (Orgs.). Temas em Geografia Rural. 1. ed. - Rio de Janeiro: EdUERJ, p. 293-318.

. (2020) Relações cidade-campo e urbano-rurais: reapresentando as urbanidades no rural como elementos constitutivos do espaço em metropolização. GEOgraphia, Niterói, v. 22, n .48.

RUA, J.; SIMONI, J. (2020) Repensando as relações urbano-rurais no ensino escolar: um diálogo entre professores. Geo UERJ, Rio de Janeiro, n. 37, e55279.

SANTOS, M. (1996) A Natureza do Espaço: técnica e tempo, razão e emoção. São Paulo: HUCITEC. 
SCHOR, J. (2015) Collaborating and Connecting: The emergence of the sharing economy. In REISCH, L.; THOGERSEN, J. Handbook on research on sustainable consumption. Cheltenham, UK: Edward Elgar. SILVA, M. R. (2017). Diferença e diferencialismo: para uma crítica da homogeneização. In: Amélia Luísa Damiani e Ricardo Baitz. (Org.). Atravessando a Geografia, Marx, Lefebvre e os Situacionistas. 1ed.São Paulo: Editora Tiragem Livre, v. 1, p. 87-108.

SIMONI, J. (2019) Múltiplas escalas de transformação nas relações urbano-rurais: o espaço rural friburguense e suas urbanidades impulsionadas pelas técnicas de informação e comunicação. Tese (doutorado) - Pontifícia Universidade Católica do Rio de Janeiro, Departamento de Geografia e Meio Ambiente, $226 \mathrm{p}$.

SOUZA, R. (1992). Territorialização do Airbnb em cidades pequenas turísticas brasileiras: regular é preciso? Dissertação (mestrado em Engenharia Civil, Arquitetura e Urbanismo) - Universidade Estadual de Campinas: Campinas, SP, $267 \mathrm{p}$.

SRNICEK, N. (2017). Platform Capitalism. 1. ed. Cambridge: Polity Press, 2017. 171p.

TAMBELLI, C. N. B. (2020) Aluga-se para temporada: o Airbnb e a cidade como negócio. Dissertação (mestrado em Geografia Humana) - Faculdade de Filosofia, Letras e Ciências Humanas da Universidade de São Paulo. 145 p.

VILLULLA, J. M. (2017) Los sonidos del silencio. Formas de resistencia de los obreros asalariados en la agricultura pampeana argentina. Revista Nera - Presidente Prudente: ano 20, nº. 35, p. 41-64.

WOODS M. (2007) Engaging the global countryside: globalization, hybridity and the reconstitution of rural place. Progress in Human Geography. Londres: Sage Publications v. 4, p. 485-507.

(2009) Rural geography: blurring boundaries and making connections. Progress in Human Geography, Londres: Sage Publications, n. 6, ano 33, p. 849-58.

WACHSMUTH, D.; ALEXANDER, W. (2018) Airbnb and the Rent Gap: Gentrification through the Sharing Economy. Environment and Planning A: Economy and Space 50, no. 6. 